\title{
$-1$ \\ AMBIENTES VIRTUAIS DE APRENDIZAGEM E A FORMAÇÃO EM EAD DAS PNEES COM LIMITAÇÃO VISUAL: UM ESTUDO DE CASO UTILIZANDO FERRAMENTAS DE INTERAÇÃO
}

\author{
Lizandra Brasil Estabel ${ }^{1}$ \\ Eliane Lourdes da Silva Moro² \\ Lucila Maria Costi Santarosa ${ }^{3}$
}

\begin{abstract}
Resumo: Este artigo relata o estudo de caso realizado em uma experiência de EAD, totalmente a distância, mediada por computador e o uso da ferramenta Bate-Papo no Ambiente Virtual de Aprendizagem (AVA) TelEduc durante a realização do PROINESP. O sujeito desse estudo é uma Pessoa com Necessidades Educacionais Especiais (PNEEs) com limitação visual. Este estudo de caso abre possibilidades para além da inclusão, da autonomia das PNEEs com limitação visual e espaço para o seu desenvolvimento, através do acesso à informação e o uso dos signos e dos instrumentos de mediação.
\end{abstract}

Palavras-Chave: Educação a distância; Informática na educação; Ambientes Virtuais de Aprendizagem; Pessoas com Necessidades Educacionais Especiais; Mediação.

Abstract: This article tells the study of case carried through in a EAD experience, total in the distance, mediated for computer and the use of the tool Chat in the Virtual Environment of Learning TelEduc during the accomplishment of the PROINESP. The citizen of this study is a Person with Educational Necessities Special with visual limitation. This study of case it opens possibilities stops beyond the inclusion, of the autonomy of the PNEEs with visual limitation and space for its development, through the access to the information and the use of the signs and the instruments of mediation.

Key-words: Learning Education; Computer Science in the education; Virtual environments of Learning; People with Educational Necessities Special; Mediation.

\section{Introdução}

A escola representa um novo papel na concepção da sociedade atual: deve ser um espaço inclusivo, que atenda as diversidades e que propicie uma educação de qualidade e que apresente respostas às necessidades de seus educandos. O aluno é o centro desse processo e a escola inclusiva deve estar preparada para propiciar a cooperação e a solidariedade, através do respeito e da valorização das diferenças, oportunizando uma educação para

\footnotetext{
${ }^{1}$ Formadora do PROINESP 2005-2006. Aluna do Doutorado de Informática na Educação - PGIE/UFRGS, Bibliotecária do Colégio Mãe de Deus e do Instituto Santa Luzia. Membro do Núcleo da Hora do Conto do DCI/FABICO/UFRGS e do Nucleo de Informática na Educação Especial (NIEE/UFRGS). E-mail:estabel@cpovo.net .

${ }^{2}$ Professora do Curso de Biblioteconomia da FABICO/UFRGS, Especialista em Informática na Educação PGIE/UFRGS, Aluna do Programa de Pós-Graduação em Educação da UFRGS - PPGEdu/UFRGS, Coordenadora do Núcleo da Hora do Conto do DCl/FABICO/UFRGS e Membro do Nucleo de Informática na Educação Especial (NIEE/UFRGS). E-mail: eliane_moro@yahoo.com.br.

3 Professora Doutora do PPGEDU e do PGIE/UFRGS, Coordenadora Nacional da RIBIE e do PROINESP, Coordenadora de pesquisa do NIEE/UFRGS, E-mail: lucila.santarosa@ufrgs.br

V. $4 \mathrm{~N}^{\circ} 1$, Julho, 2006
} 
todos e a inclusão social, digital, informacional, educacional e profissional das Pessoas com Necessidades Educacionais Especiais (PNEEs).

As pessoas que apresentam desde a ausência total de visão até a perda da projeção de luz, ao longo da história humana, ficaram por muito tempo afastadas da cultura letrada. A oralidade era a forma de acesso à informação o que dificultava a sua formação e inclusão na sociedade, pois dependiam de outra pessoa para ter acesso ao meio cultural. Vygotsky (2003, p.260) afirmava que "o princípio fundamental da educação dos cegos é o método da concepção social de seu defeito. E aqui, como em nenhuma outra parte, vemos a impotência radical da educação individual e a solução indolor do problema no plano social".

A sociedade deve ser propiciar, às PNEEs com limitação visual, condições de acesso à educação, à aprendizagem e ao desenvolvimento da mesma forma que propicia para as pessoas com visão normal. A apropriação e o uso das Tecnologias de Informação e de Comunicação (TICs) são a possibilidade de inclusão das PNEEs no cenário educacional. Através da Educação Aberta e a Distância (EAD) e do uso de Ambientes Virtuais de Aprendizagem (AVAs) é possível qualificar professores com limitação visual para atuarem com mais segurança e qualidade nos ambientes de aprendizagem.

\section{Os instrumentos, os Signos e o Outro no processo de Mediação}

Mediatore significa aquele que medeia ou intervém, surgindo daí o termo mediação. A mediação se caracteriza como a relação do homem com o mundo e com os outros homens e é de fundamental importância para que as Funções Psicológicas Superiores (sensação, percepção, atenção, memória, pensamento, entre outras) se desenvolvam. "A relação do homem com o mundo não é uma relação direta, pois é mediada por meios, que se constituem 'ferramentas auxiliares' da atividade humana. A capacidade de criar estas ferramentas é exclusiva da espécie humana". (REGO, 1995, p.42-43).

Segundo Vygotsky, dois elementos básicos são responsáveis pela mediação: o instrumento e os signos. Para a autora (Id., p.52) "Vygotsky faz uma interessante comparação entre a criação e a utilização de instrumentos como auxílio nas ações concretas e os signos, que ele chama de instrumentos psicológicos, que tem a função de auxiliar o homem nas suas atividades psíquicas, portanto internas ao individuo". As PNEEs com limitação visual, ao longo da história, ficaram em grande desvantagem em relação aos videntes. A escrita, um dos meios auxiliares do homem para controlar a própria memória, data de três a cinco mil anos da Era Cristã e somente em 1825, as pessoas com limitação visual tem acesso à cultura letrada, através do sistema de leitura tátil e escrita Braille, sistema criado por Louis Braille, que possibilita o acesso e o registro da informação por e para as pessoas com limitação visual, incluindoas na sociedade como cidadãos.

Nossa palavra escrita tem uma história muito longa. Os primeiros instrumentos de memória são signos como, por exemplo, as figuras douradas dos contadores de histórias da África Ocidental, cada uma das figuras recorda determinada história. Cada uma dessas figuras 
parece representar o nome inicial de uma longa história - por exemplo, a lua. (VYGOTSKY; LURIA, 1996, p.114).

Desde que o homem passou a registrar a informação através de signos, propiciou o armazenamento e a democratização da informação. O que antes era de domínio de apenas uma pessoa ou de um grupo pequeno, e se este fosse extinto esta informação também deixaria de existir, passou a ser disseminado e transferido para outras pessoas, inclusive para outras gerações. No entanto, a inexistência de uma forma de registro de informação por e para as pessoas com limitação visual ao longo dos anos, não os excluiu totalmente da sociedade pelo uso de um sistema de signos denominado: linguagem. Para Vygotsky, "a palavra vence a cegueira". (VYGOTSKY, 1997, p.108).

A linguagem do homem primitivo é essencialmente duas linguagens numa só: é uma linguagem de palavras e de gestos. "A linguagem do homem primitivo transmite as imagens dos objetos do modo como são percebidos pelos olhos e pelos ouvidos. O objetivo de uma linguagem desse tipo é a reprodução exata". "O homem primitivo não possui conceitos; nomes abstratos, genéricos, são completamente estranhos a ele". (VYGOTSKY; LURIA, 1996, p.126 e 130). A linguagem é a idéia concreta.

A riqueza de vocabulário do homem primitivo reflete somente a riqueza da experiência e essa riqueza é necessária - adaptar-se ou perecer. Vygotsky afirma que "os fatores mais importantes do desenvolvimento psicológico do primitivo são $o$ desenvolvimento da tecnologia $e$, em correspondência a isso, o desenvolvimento de uma estrutura social". "Para o adulto, são de grande e determinante importância as funções comportamentais que o ligam ao meio ambiente e que, por si só, são produto dessa influência social, cultural, ou seja, suas percepções, suas habilidades e seu intelecto." (VYGOTSKY;LURIA, 1996, p.148 e 156).

Desenvolvem-se a linguagem e o pensamento, surgem as idéias abstratas e criam-se inúmeras habilidades culturais e meios de adaptação. A diferenciação entre o homem cultural e o homem primitivo é o enorme repertório de mecanismos psicológicos - habilidades, formas de comportamento, signos e dispositivos culturais - que evoluíram no processo de desenvolvimento e toda sua mente se alterou sob a influência das condições complexas que o criaram.

A linguagem influencia essencialmente nos processos psíquicos do ser humano: permite lidar com a abstração, com a generalização e além da função da comunicação entre os homens, possibilita a preservação, a transmissão e a assimilação da informação através dos tempos históricos. A linguagem permite que a pessoa com limitação visual lide com os objetos exteriores mesmo estes sendo abstratos e ao fazer uso, por exemplo da palavra nuvem, através do processo de generalização, as pessoas com quem ela está interagindo compreendem a sua mensagem, pois o que é nuvem para um cego é para um vidente.

Vygotsky (1996) considera que a relação entre o uso de instrumentos e a fala afeta várias funções psicológicas, como a atenção. Afirma que essa função trata da organização do comportamento, com a criação de um determinado contexto, que prepara o homem para a percepção ou para a atividade. A função de um contexto capacita o homem de perceber os estímulos que provém do meio ambiente e de distinguir os mais importantes entre eles. $O$ estímulo cultural artificial do comportamento constitui poderoso 
aparato que afeta a personalidade e organiza sua atividade. Devem-se buscar traços da atenção em operações com determinados estímulos e signos que tornam o processo mediado e que desempenham um papel de denotação, concentração e diferenciação. Se ocorre um desempenho de denotação ocorre a comunicação, a compreensão e a percepção. Quando se realiza a concentração o sujeito reflete. Se ocorre a diferenciação ocorre a aprendizagem e a compreensão do signo. No momento que o sujeito compreende o signo, ele internaliza e passa da Zona de Desenvolvimento Proximal (ZDP) para o Nível de Desenvolvimento Real (NDR) e ocorre o desenvolvimento.

O NDR significa as conquistas já consolidadas pela pessoa, o que aprendeu e domina sozinha; o desenvolvimento proximal, ZDP constitui-se no que a pessoa pode fazer com a ajuda de outras pessoas (colega, professor, bibliotecário, especialista). "Aquilo que é a ZDP hoje será o NDR amanhã - ou seja, aquilo que a criança pode fazer com assistência hoje, ela será capaz de fazer sozinha amanhã”. (VYGOTSKY, 1984, p.98).

Para o autor "o bom aprendizado é somente aquele que adianta ao desenvolvimento" e é através da interação com o outro que acontece a superação das limitações, a solução dos problemas.

"A internalização dos sistemas de signos (a linguagem, a escrita, o sistema de números) produzidos culturalmente provoca mudanças cruciais no comportamento humano". (REGO, 1995, p.55). O desenvolvimento do indivíduo acontece a partir da interação com o meio social em que vive, pois é sempre mediado pelo outro, que atribui significados para a realidade. No momento em que os processos são internalizados estes começam a ocorrer sem a intermediação de outras pessoas, propiciando a autonomia.

Pode-se exemplificar 0 processo da mediação através de instrumentos, de signos e do outro, através da Figura 1 em que a pessoa com limitação visual realiza a ação a que se propôs.

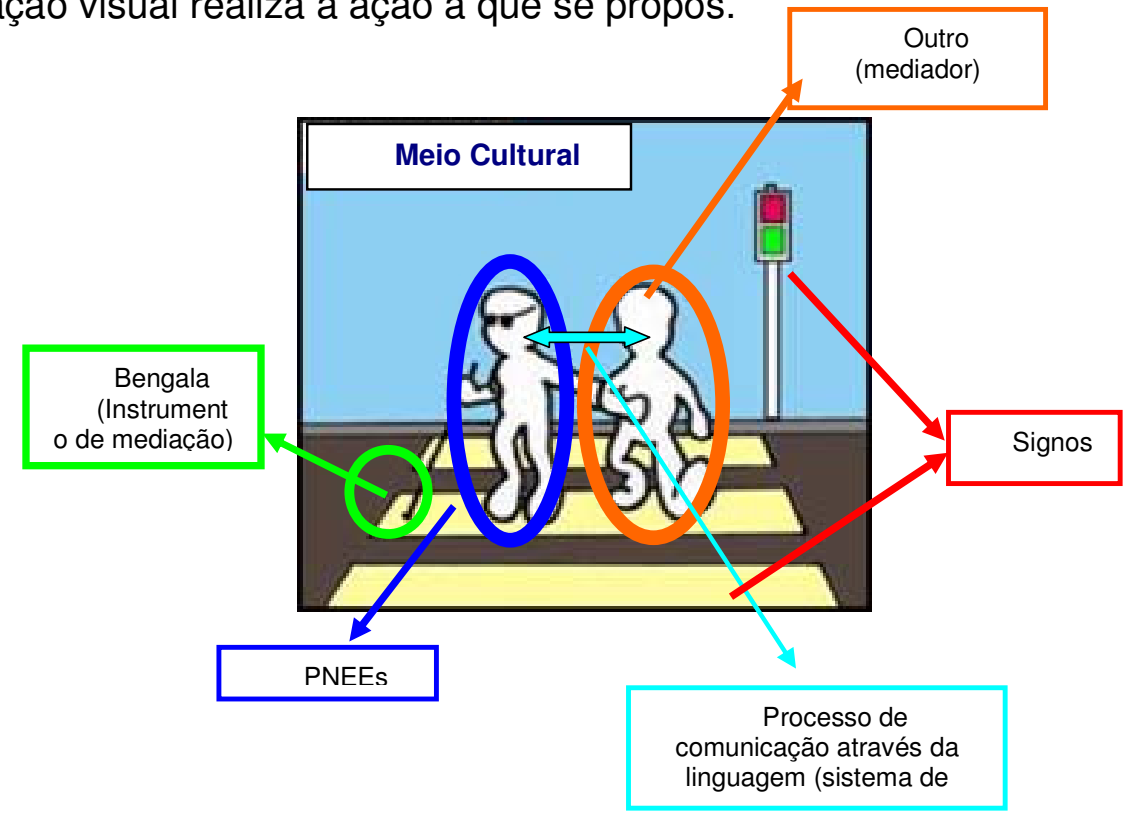

Fig 1: Mediação através de instrumentos, signos e do outro: interação 
Observa-se que o uso de signos como a bengala e os óculos escuros caracterizam uma pessoa com limitação visual. Signos convencionados culturalmente pela sociedade como a luz verde do semáforo, indicam que o pedestre pode atravessar a rua e a faixa de segurança. Pode-se verificar que o indivíduo com limitação visual, ao fazer uso da bengala, uma tecnologia assistiva que possibilita a autonomia para orientação e mobilidade, tem condições de locomover-se sozinho sem o auxílio de uma outra pessoa, mas não oferece segurança para atravessar a rua.

No entanto, apesar do semáforo apresentar a luz verde que permite a travessia do pedestre, devido à limitação visual a pessoa não pode realizar esta ação independentemente. A presença de uma outra tecnologia, o sinal sonoro, possibilitaria a realização desta ação sem a necessidade da mediação de uma outra pessoa. A necessidade de adaptação das tecnologias do meio em que se vive devem seguir os padrões de acessibilidade permitindo a autonomia e a inclusão das PNEEs na sociedade.

$\mathrm{Na}$ falta de acessibilidade, faz-se necessária a mediação do outro para a execução da atividade. No entanto, para que a PNEEs com limitação visual possa interagir com o outro e indicar o que ela deseja, é necessário o uso de um sistema de signos, a linguagem, que possibilita o processo de comunicação, propiciando a interação entre os sujeitos. As tecnologias, a acessibilidade e a interação com o outro são palavras chave para o processo de mediação e de inclusão da pessoa com limitação visual no meio cultural. A autonomia do sujeito passa pela relação com o outro, constituído socialmente no meio cultural, nas relações interpessoais, para o plano intrapessoal, através da aprendizagem gerando o desenvolvimento, de forma que a pessoa supere as suas limitações e seja incluída na sociedade.

\section{A Mediação por Instrumentos, Signos e pelo Outro e a Interação em AVAs}

Um dos fatores que os atores deste cenário devem levar em consideração, no ambiente educacional, é o papel que as TICs exercem como instrumentos mediadores do processo de ensino e de aprendizagem, através de AVAs, na estratégia educativa em que dois ou mais sujeitos constroem seu conhecimento através da discussão, da reflexão e da tomada de decisões. Os efeitos do uso da informação compartilhada entre os professores e os alunos podem encaminhar para uma rede integrada de comunicação, permitindo o estabelecimento de novas relações entre os mesmos (inter-relação de pessoas) e destes com os seus pares.

Para que cada sujeito sinta-se parte, integrado, em condições de crescimento, faz-se necessário criar espaços, ambientes de aprendizagens, reais e virtuais. No entanto, acima de tudo, deve-se capacitar profissionais que sejam encantados pelos atos de educar, de orientar, de criar.

O acesso à tecnologia expandiu o espaço da sala de aula para além de suas paredes físicas, levando professores e alunos a mergulharem em novos conhecimentos bem mais diversificados e atualizados, ao mesmo tempo em que auxiliou a superação de outras barreiras que afastam o aluno do acesso à educação, proporcionando o letramento 
e a inclusão digital. Estudos e investigações, em âmbito nacional e internacional, vêm revelando a importância e o potencial que as TICs assumem no campo da Educação Especial. Tem-se observado que a utilização pedagógica dessas tecnologias vem produzindo melhores efeitos na Educação Especial quando comparada à Educação de modo geral. Também se tem verificado que grande parte do que é planejado/aplicado a PNEEs, principalmente na área de software, resulta em benefícios a outros usuários, estendendo-se seu uso de modo generalizado. (SANTAROSA et all, 2005, p.1).

Os novos ambientes de aprendizagem exigem do educadorpesquisador a "competência de saber trocar saberes, habilidades para construir e reconstruir com seus alunos conhecimentos significativos, para conhecer 0 erro como fator de construção e saber lidar com as incertezas, as transitoriedades, os problemas”. (LOPES, 2005, p.49).

Para a realização de cursos a distância, faz-se necessária a escolha criteriosa de um ambiente que possibilite a interação dos alunos, de forma que estes sejam agentes do seu processo de aprendizado, onde o professor exerce o papel de mediador, propiciando o exercício da cooperação e da colaboração na realização das atividades.

O AVA TelEduc, é um ambiente de fácil utilização e apresenta ferramentas de comunicação como: correio eletrônico, diário de bordo, fórum de discussão, mural, bate-papo, entre outras. Estas ferramentas possibilitam que o aluno tenha autonomia para a realização das atividades propostas e possa estabelecer uma relação de comunicação com os demais componentes do grupo, sem necessitar da intervenção do formador. Este ambiente é utilizado no Programa Nacional de Informática na Educação Especial (PROINESP), da Secretaria de Educação Especial, do Ministério da Educação, ministrado pela equipe do Núcleo de Informática na Educação Especial (NIEE), da Universidade Federal do Rio Grande do Sul (UFRGS). Participam do PROINESP aproximadamente 310 professores, de 155 escolas públicas e instituições não-governamentais contempladas com laboratórios de informática. O objetivo é capacitar os professores dessas instituições a trabalharem com a informática de forma a incluir os alunos com necessidades educacionais especiais no ambiente digital, propiciando a inclusão e o exercício da cidadania.

Em uma das 14 turmas, dentre os participantes, existem 4 professores com necessidades especiais com limitação visual. Foi realizada a análise da participação de uma destas professoras, a qual denominaremos AL, desde o primeiro bate-papo realizado no curso, até a sua última participação, enfocando a necessidade, em alguns momentos da mediação de outro para auxiliá-la nos processos de participação e de interação no bate-papo.

No primeiro bate-papo, AL utilizando o leitor de telas Jaws (tecnologia assistiva que possibilita as PNEEs com limitação visual terem acesso ao computador), faz a seguinte intervenção:

AL: ... ESTOU MUITO ENROLADA. ESTA DE BATE PAPO DE VIDENTE É MUITO COMPLICADO PARA NÓS POBRES CEGOS.

$\mathrm{AL}$ faz este comentário, pois existe um outro tipo de bate-papo que é sonoro. Sua participação no primeiro encontro foi este comentário e a uma frase de despedida. 
No segundo encontro virtual, $A L$ solicita às formadoras que enviem o material do curso por e-mail, pois apresenta dificuldades de navegação no AVA. Após, escreve para as formadoras:

AL: O jaws fala tanto que me deixa um pouco maluca. Mas é gostoso conhecêlas.

Neste momento, AL começa a interagir com as formadoras, apesar de apresentar dificuldades no uso do software.

No terceiro bate-papo, AL está ao lado da outra professora com limitação visual (SB), sua colega de instituição e que tem realizado o papel de mediadora para auxiliá-la no uso das ferramentas, da mesma forma que AL busca o auxilio das formadoras. Em determinado momentos, o Jaws começa a "falar em inglês". AL busca auxílio de SB que faz a seguinte colocação:

SB: aqui estou ouvindo o papo em dose dupla, no meu micro e no da $A L$. Vou ajudar a AL que o jaws dela está falando em inglês...

Até este momento, AL tem demonstrado dependência de SB para participar dos bate-papos.

No quarto encontro, $\mathrm{AL}$ bem mais segura e demonstrando mais autonomia, faz a seguinte colocação:

$\mathrm{AL}$ : Eu quero registrar aqui que SB tem ajudado muito a gente, sempre tira nossas dúvidas, sempre compartilha as coisas novas que surgem no mundo das tecnologias, é nosso porto seguro.

Aos poucos, a apropriação, tanto do leitor de telas, quando da ferramenta do bate-papo passa a acontecer. AL começa a utilizar os dois recursos individualmente.

Em um dos últimos encontros, AL entra sozinha no ambiente:

AL: Boa noite! Que saudade de bater um papinho com vcs [vocês].

$A L$ envia mensagens para os formadores, os colegas, participa ativamente do bate-papo.

AL: [...] meus alunos adoraram a aula daquele dia, já estamos pensando em outras aulas assim. Fica bem participativo.

Em determinado momento, ela é desconectada da sala de batepapo. Minutos após, entra novamente na sala, e continua a sua participação:

AL: oi gente, caí mais voltei. [...] ajeitamos a sala hoje, ficou tudo colorido, com bandeirolas, balões, etc. As crianças adoraram participar da arrumação.

Ao término, $\mathrm{AL}$ se despede da turma, avisando que seu filho pequeno está chamando-a, pois quer dormir.

Desde o primeiro bate-papo, $A L$ demonstra um crescimento surpreendente. A mediação dos colegas e formadores, o uso de tecnologias assistivas que permitem a sua inclusão no ambiente virtual, possibilitaram a AL a interação com os demais colegas e a possibilidade de sentir-se incluída em um ambiente virtual. Em um depoimento enviado por ela para as autoras, podese constatar esta afirmação:

Agora tu me fizeste lembrar dos nossos bate papos. Ufa! menina que sufoco. No começo, levamos um tempinho até dominarmos os comandos do chat [bate-papo]. [...] Mesmo assim, quando escrevíamos uma frasezinha vibrávamos feito loucas, risos. Fomos pegar o pique no final, quando estávamos em casa. [...] Foi um desafio bem diferente. Aprendi que se quisesse podia ir além das dificuldades e aprender muito. Conheci através do micro que do outro lado existiam seres humanos mais que especiais. Pessoas que nos incentivavam sempre e que acreditavam 
que íamos conseguir de alguma forma. Obrigada por tudo e contem comigo sempre.

Segundo a epistemologia vygotskyana que apresenta os signos como elementos que permitem controlar voluntariamente as atividades psicológicas e auxiliam a ampliação das capacidades de atenção, memória e acúmulo de informação, pode-se perceber que na dialogicidade realizada no estudo com as PNEEs com limitação visual, o uso dos signos se estenderam também para os alunos dos sujeitos participantes: "meus alunos adoraram a aula daquele dia, já estamos pensando em outras aulas assim. Fica bem participativo". O uso de instrumentos provoca mudanças externas, pois possibilita a intervenção na natureza. O homem se diferencia de outras espécies, pois produz os seus instrumentos e conserva-os para uso posterior, com o objetivo de preservar e transmitir aos membros de seu grupo, sendo capaz de aperfeiçoar os antigos instrumentos e de criar novos. Através do uso das ferramentas eletrônicas dos AVAs, os signos e os instrumentos tiveram a função de regular as ações sobre os objetos, que regula as ações sobre o psiquismo das pessoas. A compensação da falta de visão foi suprida através dos instrumentos, da mediação, da interação e do uso correto dos signos.

\section{Considerações Finais}

A EAD é uma das possibilidades de incluir as PNEEs com limitação visual em um AVA, onde estas passam a ser agentes ativos do seu processo de aprendizagem. Através da interação com o outro, com o grupo, a pessoa com limitação visual sente-se parte deste universo, adquirindo autonomia e melhorando a sua auto-estima, sentindo-se capaz.

A linguagem propicia que a pessoa com limitação visual sinta-se incluída no meio em que vive através do processo de comunicação. Pode-se compreender quando Vygotsky afirma que a palavra vence a cegueira, na medida em que a pessoa com limitação visual, ao fazer uso destes signos através da fala, consegue se comunicar com o outro e se incluir no mundo em que vive. Através da mediação do "eu com o outro" e da interação entre os sujeitos é possível propiciar a participação ativa do sujeito em todos os seguimentos da sociedade e o exercício da cidadania.

Este estudo de caso abre possibilidades para além da inclusão, da autonomia das PNEEs com limitação visual e espaço para 0 seu desenvolvimento, através do acesso a informação e o uso dos signos e dos instrumentos.

Em um país de extensão continental como o Brasil, a EAD é a possibilidade de formação profissional e pessoal e de inclusão social e digital.

\section{REFERÊNCIAS}

LOPES, Rosana Pereira. Um Novo Professor: novas funções e novas metáforas. In: Redes Digitais e Metamorfose do Aprender. Petrópolis-RJ : Vozes, 2005. P.33-55. 
REGO, T. C. Vygotsky: uma perspectiva histórico cultural na educação. Petrópolis: Vozes, 1995.

SANTAROSA, Lucila Maria Costi; PASSERINO, Liliana; CARNEIRO, Mara Lucia Fernandes; GELLER, Marlise E. Ambientes Digitais de Formação de Professores a Distancia: Projeto Brasileiro de Informática na Educação Especial do MEC. Disponível em: http://www.niee.ufrgs.br/ciiee2005/dia_23/001.doc Acesso em: 16 fev. 2005.

VYGOTSKY, L. S. A Formação Social da Mente. São Paulo: Martins Fontes, 1984.

Madrid: Visor, 1997.

Obras Escogidas: fundamentos de defectologia. v.5. . Pensamento e Linguagem. São Paulo: Martins Fontes, 1987.

Psicologia Pedagógica. Porto Alegre: Artmed, 2003.

VYGOTSKY, L. S; LURIA, A. R. Estudos sobre a História do Comportamento: o macaco, o primitivo e a criança. Porto Alegre: Artes Médicas, 1996. 